\title{
LIPOFILLING - DIFFERENT TECHNIQUES, SIMILAR RESULTS - EXPERIENCE OF THE ONCOPLASTIC COURSE OF SBM DE JAÚ - SP
}

Paulus F. M. Ramos¹, Maurício de A. Resende¹, Ailton Joioso', João R. A. Paloschi', Alice J. Pereira

${ }^{1}$ Hospital Amaral Carvalho - Jaú (SP), Brazil.

Objectives: To analyze the experience with the surgical technique of lipoenxertia of the Hospital Amaral Carvalho in Jaú - SP, during the first course of Oncoplastica by the Brazilian Society of Mastology. Methodology: Retrospective analysis of a series of cases, in which the lipofilling technique was used, carried out in the 1st Oncoplastic course of SBM of Jaú - SP in the year 2016-2017. Eight patients were identified using this technique. Their indications, techniques used and results were evaluated by pre and post operative photographic comparison. Results: During the course, eight cases were performed with the lipofilling technique in the 12 modules, of a total of 103 patients operated and 198 procedures performed. The mean age of patients submitted to lipofilling was 48.8 years (range 31-66 years). The median volume of injected fat was $232.5 \mathrm{~mL}$ (range $40-500 \mathrm{~mL}$ ). The surgeries were indicated with three specific purposes: one (01) case for preparation of the recipient bed of the reconstruction that had been irradiated and the skin was not of good quality; two (02) cases of breast defect repair after conservative surgeries in irradiated breasts; and five (05) cases to improve breast contours in reconstructed breasts ( 4 cases of autologous tissue and 1 case of reconstruction with prosthesis). Two techniques were used, Colleman and Colleman modified, the latter with acquisition of larger volumes of fat. The pre and post operative photographic studies did not show important aesthetic differences with the two techniques. Conclusions: It is an important refinement technique, technically and oncologically safe, which improves the initial surgeries. Very common in oncoplastic is the need for a second intervention to correct defects, whether large or small, and this technique should be included in the arsenal of breast surgeons. When we think of patients previously submitted to radiotherapy and need new surgical intervention, this procedure becomes almost mandatory. 